\title{
RECENT EPIDEMIOLOGICAL RESULTS OF THYROID CANCER IN THE MOST RADIATED TERRITORY IN POLAND
}

\author{
Andrzej Tukiendorf', Leszek Miszczyk², Phil McE wan ${ }^{1}$ \\ ${ }^{1}$ Cardiff Research Consortium - Capita Health Division, Cardiff, U.K. \\ ${ }^{2}$ Institute of Oncology, Maria Skłodowska-Curie Memorial Institute, Gliwice, Poland
}

\begin{abstract}
SUMMARY
In this report the authors evaluate epidemiological evidence of thyroid cancer cases in a highly radiated territory in Poland - i.e. in the province of O pole after 1986. The analysis - based on logistic regression modelling of registered thyroid cancer and an ecological covariate ${ }^{137} \mathrm{C} S$ concentration) - shows differences in incidence in six distinguished radiation zones and two equal periods. The results of this study indicate a significant increase in incidence of thyroid cancer in 1995-2002 in males and in females comparing to the years 1987-1994. Moreover, a considerable rise of incidences has been noticed in the elevated isotope's concentration zones in females across the province in the analyzed periods.

The data comprises all the thyroid cancer cases registered in Opole province in the years 1987-2002. The data originated from the Provincial Cancer Registry in Opole.

The information on ${ }^{137} \mathrm{C}$ s concentrations was derived from the Polish Geological Institute in Warsaw. The computation was performed using WinBUGS software.
\end{abstract}

Key words: thyroid cancer, radiation, Chernobyl disaster, logistic regression, WinBUGS

Address for correspondence: P. McEwan, Cardiff Research Consortium - Capita Health Division, Eastgate House, 35-43 NewportRoad, Cardiff, CF24 OAB, U.K. E-mail: phil.mcewan@ capita.co.uk

\section{INTRODUCTION}

Cancer has long been known to be caused by a risk from exposure to radiation. Hence, the Chernobyl disaster (1986) causing extensive radioactive pollution in Europe could affectively increase cancer morbidity in the contaminated parts of the continent. However, the assessment of the effects on health from exposure to ionizing radiation is a matter of considerable controversy, especially in studies of exposure to low doses.

Thyroid cancer is a fairly rare malignancy. The thyroid gland cells grow uncontrollably to form tumors and can invade the tissues of the neck, spread to the surrounding lymph nodes, or to the bloodstream and then to other parts of the body. There are four types of thyroid cancer some of which are much more common than others (incidence in Upper Silesian women in parentheses): papillary (61\%), follicular (23\%), anaplastic (5-10\%), medullary (3-6\%), and Hurthle cell $(\sim 2 \%)(1,2)$. The development of cancer is multi-factorial process, there is no single cause of cancer, only factors that contribute to cancer development.

People with certain inherited medical conditions are also at higher risk of thyroid cancer. About $20 \%$ of medullary thyroid carcinomas (MTCs) result from inheriting an abnormal gene. These cases are known as familial medullary thyroid carcinoma (FMTC - MTC alone) or type 2 multiple endocrine neoplasia (MEN2 - MTC in combination with tumors of other endocrine glands). If FMTC or MEN2 runs in a family, then they may be at a very high risk of developing MTC.
Thyroid cancers occur more often in women than in men (at a ratio of three to one). Moreover, most cases of papillary and follicular thyroid cancer are found in people between the ages of 30 and 50 years.

An associated risk factor with an increased chance of developing thyroid cancer is diet low in iodine. It has been established that papillary and follicular thyroid cancers are more common in areas of the world where people's diets are low in iodine.

Among others, radiation as a risk factor for thyroid cancer has received more attention in science and the press recently. People exposed to high levels of radiation are much more likely than others to develop papillary or follicular thyroid cancer. For instance, one important source of radiation exposure is treatment with radiotherapy. Scientists found that people who had received radiation for the thyroid gland had increased risk of developing thyroid cancer. Several studies have pointed to an increased risk for benign thyroid nodules, and possibly cancer, due to radioactive fallout from nuclear weapons or power plant accidents. There appears to be more cases of thyroid cancer in children living near the Ukrainian city of Chernobyl, the site of a 1986 nuclear plant accident that exposed millions of people to fallout. People involved with the cleanup after the accident and those who lived near the plant in Ukraine and Belarus have also had a higher rate of thyroid cancer, even though they were adults. However, recent information shows that some fallout occurred over certain regions of the United States (after nuclear weapons testing in western states during the 1950s), where this exposure was much lower than around Chernobyl, a heightened risk of thyroid cancer has not been proven (based on 3,4). 
Table 1. Thyroid cancer cases and the population with crude rates in distinguished radiation zones in Opole province in 1987-1994 and 1995-2002 periods

\begin{tabular}{|c|c|c|c|c|c|c|c|c|c|c|c|c|}
\hline \multirow{2}{*}{$\begin{array}{l}\text { Gender } \\
\text { Periods }\end{array}$} & \multicolumn{6}{|c|}{ Males } & \multicolumn{6}{|c|}{ Females } \\
\hline & 1987- 1994 & $1990 / 1991$ & \multirow{2}{*}{$\begin{array}{l}\text { Crude } \\
\text { rates }\end{array}$} & 1995-2002 & 1998/1999 & \multirow{2}{*}{$\begin{array}{l}\text { Crude } \\
\text { rates }\end{array}$} & 1987-1994 & 1990/1991 & \multirow{2}{*}{$\begin{array}{l}\text { Crude } \\
\text { rates }\end{array}$} & \multirow{2}{*}{\begin{tabular}{|c|} 
Cases \\
\end{tabular}} & \multirow{2}{*}{\begin{tabular}{|c|}
$1998 / 1999$ \\
Population \\
\end{tabular}} & \multirow{2}{*}{$\begin{array}{l}\text { Crude } \\
\text { rates }\end{array}$} \\
\hline $\begin{array}{l}\text { Zone } \\
{\left[\mathrm{kBq} / \mathrm{m}^{2}\right]}\end{array}$ & Cases & Population & & Cases & Population & & Cases & Population & & & & \\
\hline$[0,10)$ & 14 & 257,416 & $5,44 \mathrm{E}-05$ & 22 & 251,688 & $8,74 E-05$ & 48 & 266,531 & $18,0 \mathrm{E}-05$ & 83 & 262,986 & $31,6 \mathrm{E}-05$ \\
\hline$[10,20)$ & 1 & 64,037 & $1,56 \mathrm{E}-05$ & 5 & 63,628 & $7,86 \mathrm{E}-05$ & 17 & 68,574 & $24,8 \mathrm{E}-05$ & 20 & 67,859 & $29,5 \mathrm{E}-05$ \\
\hline$[20,30)$ & 8 & 104,024 & 7,69E-05 & 10 & 104,568 & $9,56 \mathrm{E}-05$ & 19 & 112,544 & $16,9 \mathrm{E}-05$ & 58 & 113,925 & $50,9 \mathrm{E}-05$ \\
\hline$[30,40)$ & 2 & 52,752 & $3,79 \mathrm{E}-05$ & 3 & 53,042 & $5,66 \mathrm{E}-05$ & 12 & 54,676 & $21,9 \mathrm{E}-05$ & 23 & 55,554 & $41,4 \mathrm{E}-05$ \\
\hline$[40,50)$ & 0 & 10,248 & 0 & 2 & 10,117 & $19,8 \mathrm{E}-05$ & 1 & 10,740 & $9,31 E-05$ & 7 & 10,490 & $66,7 \mathrm{E}-05$ \\
\hline$[50,80)$ & 0 & 5,065 & 0 & 0 & 5,016 & 0 & 1 & 5,071 & $19,7 \mathrm{E}-05$ & 1 & 4,995 & $20,0 \mathrm{E}-05$ \\
\hline
\end{tabular}

Table 2. Estimates of time and radiation logistic regression parameters

\begin{tabular}{|l|c|c|c|c|c|c|}
\hline \multirow{2}{*}{ Gender } & Parameter & Mean & $\begin{array}{c}\text { Standard } \\
\text { deviation }\end{array}$ & $\begin{array}{c}\text { Credible 95\% } \\
\text { interval }\end{array}$ & p-value & DIC \\
\hline \multirow{2}{*}{ Males } & $\beta_{1}$ & 0.53 & 0.25 & $(0.051,1.032)$ & 0.0157 & 44.86 \\
\hline \multirow{2}{*}{ Females } & $\beta_{2}$ & -0.0355 & 0.101 & $(-0.239,0.1544)$ & 0.628 & \\
\cline { 2 - 8 } & $\beta_{1}$ & 0.676 & 0.121 & $(0.437,0.916)$ & $<0.0001$ & 67.15 \\
\hline
\end{tabular}

A possible influence of radiation on thyroid cancer after the Chernobyl disaster was the subject of dozens of scientific papers so far. For example, Jacob (5) shows that the excess absolute risk per unit thyroid dose for the birth cohort 1971-1985 by the Monte Carlo analysis was 2.1 cases per 104 person-year Gy, and the excess relative risk per unit thyroid dose was $23 \mathrm{~Gy}-1$. Reports on a great increase in the frequency of thyroid cancer in children in Belarus, where incidence started to rise in 1990 and continues in some regions of Belarus, can be found in (6), or in (7). In turn, Williams et al. (8) suggest that the initial mutation at the time of exposure played a major role in tumour latency and aggressiveness. Some skeptical opinions that Chernobyl effects are not threatening have also appeared in the scientific literature (see e.g. 9).

The first research on thyroid cancer in Opole province in relation to radiation was conducted by Tukiendorf et al. (10), and the results suggest an increasing risk of the thyroid cancer compaired to all cancers within the highly radiated territories.

\section{MATERIALS}

The data concerning all the registered cases of the analyzed thyroid cancer (193, ICD-9; C73, ICD-10) in males and females (all ages) were obtained from the Provincial Cancer Registry in Opole [the contributor to the International Agency for Research on Cancer and International Association of Cancer Registries (11)]. In the analyzed first eight-year period (1987-1994) 25 malignancies were confirmed in males and 98 in females. In the second analyzed period (1995-2002), the respective numbers of 40 and 192 were registered.

The population data originated from the 1988 and 2002 National Censuses. The mid year population for the analyzed periods, i.e. 1990/1991 and 1998/1999 was consisting of 493,542 and 488,059 permanent male and 518,136 and 515,809 female residents, respectively.

The information on ${ }^{137} \mathrm{Cs}$ concentration rates in Opole province originated from the state monitoring provided by the Polish Geological Institute in Warsaw (1993). The precise spectrometric survey of the abnormally polluted territory [so-called 'Opole anomaly' (12)] consisted of 3,224 measurement points. Up to now, the recorded concentration rates of ${ }^{137} \mathrm{Cs}$ are the best available representation of the radiation emitter in the region under study.

The present epidemiological analysis was conducted for the former province’s administration division standing till 1999.

\section{METHODS}

To study the thyroid cancer in relation to ${ }^{137} \mathrm{Cs}$ concentrations six radiation zones for $\mathrm{kBq} / \mathrm{m}^{2}$ bands $(0,10),(10,20),(20,30)$, $(30,40),(40,50)$, and $(50,80)$ were distinguished via the geostatistical kriging interpolation method (13) using GIS (Fig. 1).

The epidemiological and demographic numbers within the distinguished radiation zones are reported in Table 1.

The data displayed in Table 1 was basic for the further statistical analysis.

The statistical analysis was based on Bayesian modeling using fixed-effects logistic regression that incorporated an ecological covariate $\left({ }^{137} \mathrm{Cs}\right.$ concentration). In the model

$$
r_{i} \sim \operatorname{Binomial}\left(\pi_{i}, n_{i}\right)
$$

where $r_{i}$ is the number of cancer cases within the ${ }^{137}$ Cs exposure zone and the period, $\mathrm{ni}$ - the respective population 'at risk', and $\operatorname{logit}\left(\pi_{i}\right)=\alpha+\beta_{1} X_{i 1}+\beta_{2} X_{i 2}$, 


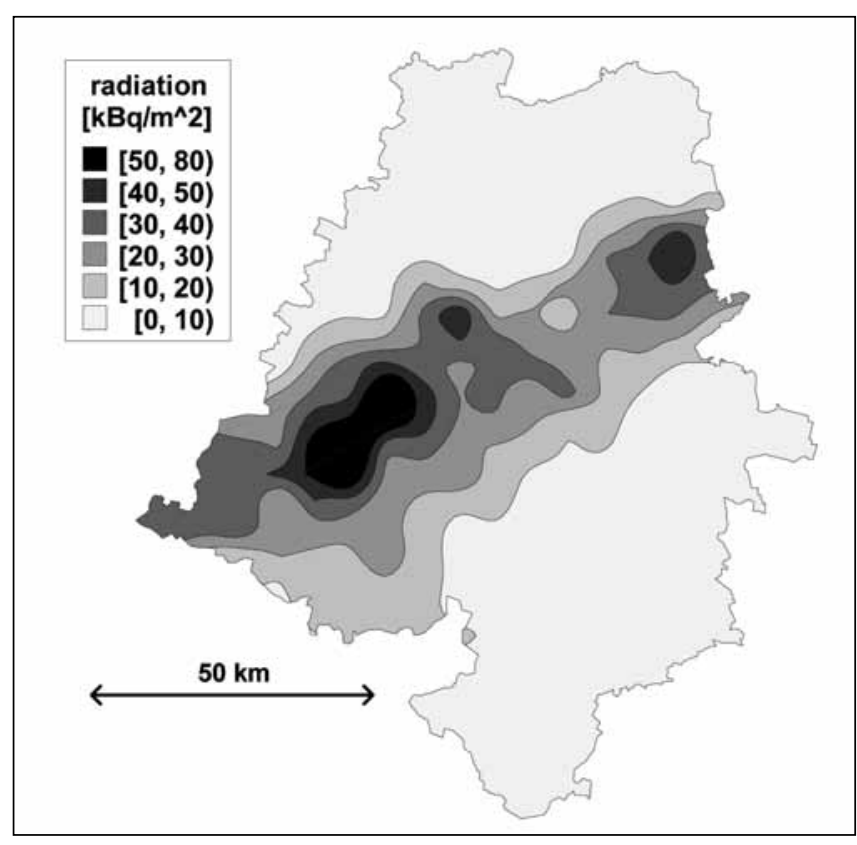

Fig. 1. Radiation zones in Opole province for ${ }^{137} \mathrm{Cs}$ concentration (1993).

is the logistic regression model with a general relative risk function of $x$ (period/cesium two-dimensional categorical variable). In the supposed regression function, $x_{i 1}$ denotes the analyzed periods, while $x_{i 2}$ the following ${ }^{137} \mathrm{Cs}$ exposure zones, while this ordering of categories provides the lower regression function as baseline [cf. (14)]. The incidence probabilities $\pi_{i}$ were calculated for the particular radiation levels as well as for the chosen time bands.

The computation was performed in WinBUGS version 1.4 (15). To achieve the convergence the first 1000 samples were discarded (as a 'burn-in' samples) while the following 10,000 cycles ('production run') of the Gibbs sampler were used to estimate each quantity of interest.

The WinBUGS codes used in this study are available from the authors upon request.

\section{RESULTS}

The posterior estimates of the slope regression parameters (with p-values) are reported in Table 2.

The posterior analysis of the $\beta_{1}$ slope regression parameter and its $p$-value testifies an increasing thyroid cancer incidence both in males and females in years following Chernobyl accident in 1986. Simultaneously, at the $p$-value $<0.025$, an increasing tendency to suffer from the disease is observed in females with elevating ${ }^{137} \mathrm{Cs}$ concentration - see $\beta_{2}$ estimates for females (Table 1 ); this effect in males is not observed. The contributions of time and radiation exposure to endemic male and female incidences are presented in Figure 2.

The results displayed in Figure 2 confirm the morbidity trends estimated via the slope regression parameters (Table 1). The incidence in males is greater in the years 1995-2002 than in $1987-1995$ by about $60 \%$ but no relation with exposure was found. However, in females, the modeled data show that morbidity is positively correlated with an increase of radiation; these values for the second period are approximately twice as high as for the first analyzed time band.

\section{CONCLUSION}

A risk factor for cancer is anything that increases a person's chance of getting the disease. As it was said earlier, there are at least a few risk factors that make a person more likely to suffer from thyroid cancer. The presented results confirm that one of these could be radiation. However, they are difficult to interpret and at this stage of the study they require careful inference. Generally, the discussion over the conducted research can be directed to the following points:

- If radiation could have really caused the thyroid cancer in the region, then it seems to be logical that the incidence (both in males and females) was elevated in the second analyzed eightyear period (after the Chernobyl disaster) in comparison to the first one, since some scientific reports estimate that there is typically a long-term delay between radiation exposure and the development of cancer, reaching even 20 or more years (15). On the other hand, it needs to be stressed that a short latency is also associated with the thyroid's tumours, as it has been reported that large numbers of papillary thyroid cancer could occur in those exposed to high levels of short-lived isotopes in fallout after the Chernobyl disaster (8).

- In the case of incidence in females included in the study, the aspects of time and exposure seem reasonable factors that affect the correlation between radiation and the cancer especially in the second period of 1995-2002, where the trend is much more steeper. Still not many years have elapsed from the time when the power plant exploded to affect considerably the thyroid cancer incidence.

Finally, these observations are worthy of academic and public concern, as there is evidence that the link between radiation and time of thyroid cancer onset is consistent. However, due to a particularly rare disease and a small area studied and small number of cases observed, one must adopt a cautious attitude towards such

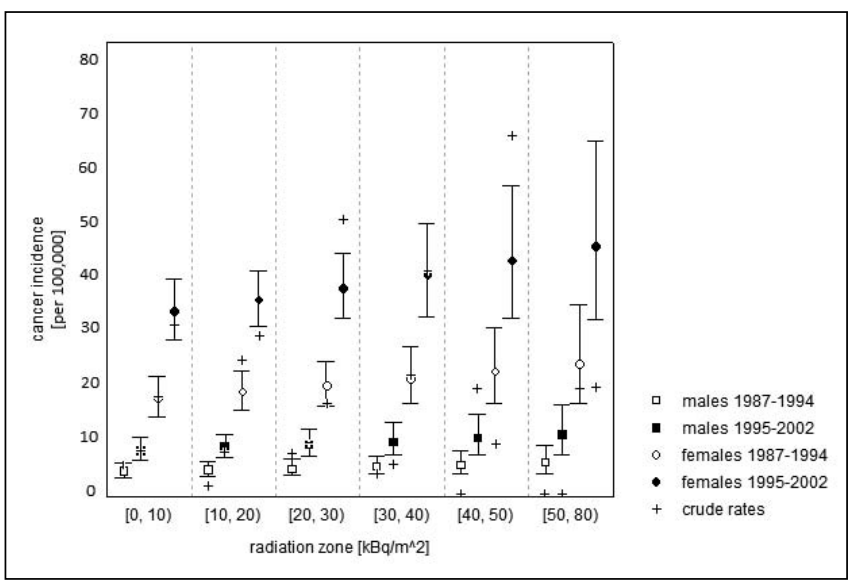

Fig. 2. Thyroid cancer incidence in periods 1987-1994 and 1995-2002 within ${ }^{137}$ Cs concentration zones in Opole province (with credible 95\% intervals). 
findings to avoid any dogmatic interpretation. Further studies in this field are needed to clarify the problem under discussion.

\section{Acknowledgements}

The authors would like to thank the two anonymous Referees for many constructive comments on an earlier draft.

\section{REFERENCES}

1. Zemła B. Thyroid cancer incidence among Silesian women following a histopathological structure. Pol J Endocrinol. 2001;52(3):397-412. (In Polish.)

2. Norman J. Thyroid cancer [Internet]. Montclair: Vertical Health, LLC; 2004 [cited 2010 Apr 23]. Available from: http://www.endocrineweb. com/thyroidca.html.

3. What are the risk factors for thyroid cancer? [Internet]. Atlanta: American Cancer Society, Inc; 2003 [cited 2010 Apr 23]. Available from: http:// www.cancer.org/docroot/CRI/content/CRI_2_4_2X_What_are_the_risk_ factors_for_thyroid_cancer_43.asp?rnav=cri.

4. Thyroid cancer: who's at risk? [Internet]. Bethesda: National Cancer Institute; 2004 [cited 2010 Apr 23]. Available from: http://www.cancer. gov/cancertopics/wyntk/thyroid/page4.

5. Jacob P, Kenigsberg Y, Zvonova I, Goulko G, Buglova E, Heidenreich WF, et al. Childhood exposure due to the Chernobyl accident and thyroid cancer risk in contaminated areas of Belarus and Russia. Br J Cancer. 1999 Jul;80(9):1461-9.
6. Kazakov VS, Demidchik EP, Astakhova LN. Thyroid cancer after Chernobyl. Nature. 1992 Sep 3;359(6390):21.

7. Jacob P, Goulko G, Heidenreich WF, Likhtarev I, Kairo I, Tronko ND, et al. Thyroid cancer risk to children calculated. Nature. $1998 \mathrm{Mar}$ 5;392(6671):31-2.

8. Williams ED, Abrosimov A, Bogdanova T, Demidchik EP, Ito M, LiVolsi $\mathrm{V}$, et al. Thyroid carcinoma after Chernobyl latent period, morphology and aggressiveness. Br J Cancer. 2004 Jun 1;90(11):2219-24.

9. Dickman S. Chernobyl effects not as bad as feared. Nature. 1991 May;351(6325):335.

10. Tukiendorf A, Krasowski G, Rybak Z. Thyroid cancer morbidity in Opole province, Poland, after Czernobyl disaster. Cent Eur J Public Health. 2003 Jun;11(2):98-101.

11. Parkin DM, Muir CS, Whelan SL, Gao YT, Ferlay J, Powell J, editors. Cancer incidence in five continents. Vol. VI. IARC Scientific Publications no. 120. Lyon: IARC; 1992.

12. Strzelecki R, Wołkowicz S, Szewczyk J, Lewandowski P. Radioecological maps of Poland. Warsaw: Polish Geological Institute; 1993. (In Polish.)

13. Keckler D. SURFER for Windows: user's guide. Golden: Golden Software, Inc.; 1995.

14. Congdon P. Bayesian statistical modelling. Chichester: Wiley; 2001.

15. Norman J. Thyroid nodules [Internet]. Montclair: Vertical Health, LLC; 2004 [cited 2010 Apr 23]. Available from: http://www.endocrineweb. com/nodule.html.

Received January 4, 2010 Accepted in revised form April 23, 2010 